\title{
Comparison of Serum Valproic Acid Determination Through Gas and High Performance Liquid Chromatography Methods
}

\author{
Ali Nazeri ${ }^{1}$; Maryam Jalali ${ }^{2}$; Mehri Aliasgharpour ${ }^{1,4} ;$ Farideh Khosravie $^{2}$ \\ ${ }_{1}^{1}$ Reference Health Laboratory Research Center, Ministry of Health and Medical Education, Tehran, IR Iran \\ ${ }^{2}$ Noor Pathobiology Laboratory, Tehran, IR Iran \\ ${ }^{*}$ Corresponding author: Mehri Aliasgharpour, Reference Health Laboratory Research Center, Ministry of Health and Medical Education, Tehran, IR Iran. Tel: +98-9124713790, Fax: +98- \\ 2166728121, E-mail: aliasgharpour@health.govir
}

Received: May 11, 2013; Revised: June 24, 2013; Accepted: August 2, 2013

\begin{abstract}
Background: Valproic acid is widely used as an anticonvulsant and mood-stabilizing drug in the treatment of epilepsy. Determination of serum valproic acid is required in epilepsy therapy for efficient control of seizures.

Objectives: In the present study, the gas chromatography method was applied to determine serum valproic acid and resulting data were compared with those obtained by high performance liquid chromatography.

Materials and Methods: Two methods were used: assayed patients' serum samples and serum quality control materials for laboratory diagnostics applied to high performance liquid chromatography (HPLC) and gas chromatography (GC). All chemicals had a grade suitable for analysis.

Results: The obtained results in both systems were in agreement regarding linearity, correlation and recovery. The results revealed a lower GC limit of quantification $(8 \mu \mathrm{g} / \mathrm{mL})$, a better intra-assay coefficient of variation (CV) $(3.86 \%-3.99 \%)$ and inter-assay CV $(6.14 \%-6.42 \%)$ for all three levels of control materials. In addition, a shorter run time of the GC vs. the HPLC chromatographic step (6 minutes vs. 17 minutes) was observed.

Conclusions: The present study reports a short run time of the chromatographic step as well as a good sensitivity for the GC method. Furthermore, the significance of this method is the simplicity in sample preparation step without the need for derivatization and specific detector ensuring cost-effectiveness for the GC analysis. In summary, in comparison with HPLC method, our obtained data illustrate a good performance of the GC analytical procedure and confirm its usefulness for the routine quantification of valproic acid level in patients' serum specimens.
\end{abstract}

Keywords: Valproic Acid; Chromatography, Gas; Chromatography, High Pressure Liquid; Epilepsy

\section{Background}

Valproate (2-propylpentanoate) is available as valproic acid (N-dipropylacetic acid), sodium valproate and semisodium valproate, which are widely used as anticonvulsants and mood-stabilizing drugs, primarily in the treatment of epilepsy. Recently, several investigations have proposed its use in the treatment of anxiety, alcoholism, schizophrenia, borderline personality disorder and mood disorders including bipolar disorder (1). It is less commonly used in the treatment of major depression $(1,2)$. Valproic acid acts on dopamine and glutamine neurotransmission as well as intracellular signaling (3). Valproic acid is marketed under various pharmaceutical preparations and forms. However, the circulating active molecule is the "valproate ion", which is characterized by dose limited absorption, nonlinear plasma protein binding and multiple metabolic pathways of elimination (2). Once absorbed, valproic acid is largely bound to plasma proteins with a relatively small distribution volume (2, $4)$. Its concentration in cerebrospinal fluid is approximately one-tenth of that in plasma and is directly correlated with the concentration found in tears. At therapeutic ranges (50 - $100 \mathrm{mg} / \mathrm{L}$ or $346-693 \mu \mathrm{mol} / \mathrm{L}$ ) (5), valproic acid half-life varies from 10 to 20 hours in adults, to a significantly shorter duration (6 - 9 hours) in children (4). Numerous metabolites of valproic acid have been identified since it undergoes extensive liver metabolism. Furthermore, many different evidences suggest that several of the valproic acid metabolites contribute to its pharmacological actions or toxicity $(4,5)$. Common adverse effects of valproate treatment include weight gain, gastrointestinal symptoms, sedation, tremor, heartburn, impaired vision, hearing loss, respiratory depression, headache, joint pain and mild elevation of liver enzymes (3). Severe hepatotoxicity is rare in adults and many adverse 
effects are dose related and resolve with dose reduction (3). Overdose in children is usually of accidental origin, whereas in adults it is more likely to be an intentional act. In spite of these effects, use of valproate has the advantage of being easy to manage and it is also well tolerated in long term among patients. In severe intoxications, hemoperfusion or hemofiltration can be an effective means of quick elimination of the drug from the body.

\section{Objectives}

Determination of valproic acid in serum is required in epilepsy therapy for efficient control of seizures and its serum monitoring is often accomplished by using different techniques. Literature reviews indicate that many different methods including high performance liquid chromatography, gas chromatography and immunological assays for valproic acid determination in patients serum are purposed (6-10). Most of the procedures prior to HPLC separation are complicated and time consuming. Furthermore, several GC analysis with flame ionization detector use different solvents as well as solid phase extraction columns and various internal standards (7). In order to minimize valproic acid adverse effects and maximize its therapeutic activity, the determination of the se$\mathrm{rum} /$ plasma concentration is critical and the utilization of a rapid, sensitive, simple and cost effective method for its therapeutic monitoring is necessary (11). In the present study we developed, compared, and evaluated valproic acid determination in serum samples by GC and HPLC methods for diagnostic and monitoring purposes of patients under treatment with valproic acid.

\section{Materials and Methods}

Two systems (The Agilent 1260 Infinity HPLC-Chip/MS system, Agilent Technologies, Santa Clara, California, the USA for HPLC assays and the Agilent 6890 GC, Agilent Technologies, Santa Clara, California, the USA, system for GC assays) were used. Samples assayed were patients' serum and Chromsystems, Chromsystems GmbH, Munich, Germany, as a serum quality control material. All chemicals had a grade suitable for analysis.

\subsection{Instruments Set-up}

\subsubsection{HPLC}

The HPLC Agilent 1260 Infinity Series with a C18 column (15 cm length) and inside diameter of $4.6 \mathrm{~mm}$ was used. The analysis was performed at $40{ }^{\circ} \mathrm{C}$. The UV absorption spectrometer was used as a HPLC detector at a detection wavelength of $210 \mathrm{~nm}$. The mobile phase consisted of $0.02 \mathrm{M}$ phosphate buffer $(\mathrm{pH}=3.0)$ and acetonitrile-water 65:35 (v/v) that were filtered separately before mixing. A flow rate of $1 \mathrm{~mL} / \mathrm{min}$ was selected and the internal standard solution was $20 \mu \mathrm{g} / \mathrm{mL}$ butabarbital (6).

\subsubsection{Gas Chromatography (GC)}

Gas chromatography was performed on the Agilent $6890 \mathrm{~N}$ GC System, with flame ionization detector and a HP-1 column in (30 m x $0.53 \mathrm{~mm}$ ). The initial temperature of the column oven was $80{ }^{\circ} \mathrm{C}$, with nitrogen carrier gas. A flow rate of $15 \mathrm{~mL} / \mathrm{min}$ and a split of 1/10 were selected. The internal standard solution was $20 \mu \mathrm{g} / \mathrm{mL}$ n-caproic acid (7).

\subsection{Extraction Procedures}

\subsubsection{Valproic Acid (HPLC)}

A volume of $200 \mu \mathrm{L}$ of either serum/control material (three levels) was added to the test tubes. Afterword, 50 $\mu \mathrm{L}$ of internal standard $(20 \mu \mathrm{g} / \mathrm{mL}$ butabarbital $)$ and 200 $\mu \mathrm{L}$ of $\mathrm{HCl} 1 \mathrm{~N}$ were added and mixed on a vortex mixer for 5 seconds. Later, $500 \mu \mathrm{L}$ of dichloromethane were added and mixed on a vortex mixer for 30 seconds, then centrifuged at $3000 \mathrm{rpm}$ for 10 minutes. The organic layers were taken and added to another set of test tubes and evaporated at $400{ }^{\circ} \mathrm{C}$ with nitrogen gas. Then, the content of the tubes was dissolved with $50 \mu \mathrm{L}$ methanol and $20 \mu \mathrm{L}$ of the resulting product were injected for analysis. The peaks were visible at 4.1 minutes for internal standard and at 13.6 minutes for valproic acid.

\subsubsection{Valproic Acid (GC)}

A volume of $200 \mu \mathrm{L}$ of either serum/control material (3 levels) was added to the test tubes, followed by $50 \mu \mathrm{L}$ of internal standard $(20 \mu \mathrm{g} / \mathrm{mL}$ n-caproic acid) and $200 \mu \mathrm{L}$ $\mathrm{HCl} 1 \mathrm{~N}$ which were mixed on a vortex mixer for 5 seconds. Later, $200 \mu \mathrm{L}$ of chloroform was added and mixed on a vortex mixer for 30 seconds, then centrifuged at 3000 rpm for 10 minutes and finally, $1 \mu \mathrm{L}$ of the organic layers was injected. The peaks were visible at 2.8 minutes for internal standard and at 4.1 minutes for valproic acid.

\subsection{Comparison and Evaluation Studies}

\subsubsection{Precision Studies}

We performed intra and inter-assays precision evaluation of the two systems by first reconstituting and then pooling three vials (three levels) of chromsystems quality control materials. Intra-assay precision was determined by analyzing a pool serum sample (each level; $n=10 \mathrm{X}$ ) in one day. Inter-assay precision was determined by analyzing a pool serum in 20 days.

\subsubsection{Recovery Studies}

Stock valproic acid standard solution (1000 $\mu \mathrm{g} / \mathrm{mL})$ in methanol was prepared and was kept in the freezer $\left(-20^{\circ} \mathrm{C}\right)$. Then, serum samples with blank and $75 \mu \mathrm{g} / \mathrm{mL}$ valporic acid concentrations were prepared and the recovery percentage in both systems was calculated. 


\subsubsection{Limit of Quantification}

The limit of quantification (LOQ) is the lowest concentration of analyte in a sample that can be determined with acceptable precision and accuracy. Furthermore, LOQ is quoted $(12,13)$ as the concentration yielding a signal-to-noise ratio of 10:1 and confirmed by analyzing a number of samples near this value $(n=5)$.

\subsubsection{Linearity Studies}

For linearity studies, valproic acid concentrations of $25 \mu \mathrm{g} /$ $\mathrm{mL}, 50 \mu \mathrm{g} / \mathrm{mL}, 100 \mu \mathrm{g} / \mathrm{mL}, 200 \mu \mathrm{g} / \mathrm{mL}$ and $400 \mu \mathrm{g} / \mathrm{mL}$ were added to neat pool serums and analyzed in both systems.

\subsubsection{Correlation studies}

For this purpose, the heparinized serum samples of 60 patients (25 males and 35 females) on valproic acid treatment and in different age range were selected, and the obtained results were compared.

\section{Results}

With respect to Chromsystems serum quality control material values (Table 1), obtained results for the intraassay and inter-assay precision studies revealed a superior precision (lower CV) for GC than for HPLC in valproic acid determination (Table 2). Table 3 indicates the recovery percentage of added valproic acid in both systems. Figure 1 and 2 reveal the results obtained for the linearity studies in the linear range of $25-400 \mu \mathrm{g} / \mathrm{mL}$ for valproic acid. The limits of quantification values were $25 \mu \mathrm{g} / \mathrm{mL}$ for HPLC and $8 \mu \mathrm{g} / \mathrm{mL}$ for GC, respectively. Moreover, patients serum samples analysis correlated well in both systems $\left(\mathrm{R}^{2}=0.98\right)$ (Figure 3 ).

Table 1. Values of Chromsystem Control Materials for Valproic Acid

\begin{tabular}{lll}
\hline & Target Value, $\boldsymbol{\mu g} / \mathbf{m L}$ & Range, $\boldsymbol{\mu g} / \mathbf{m L}$ \\
\hline Level I & 40.20 & $32.20-48.20$ \\
Level II & 102 & $81.50-122.0$ \\
level III & 150 & $120-180.0$ \\
\hline
\end{tabular}

\begin{tabular}{|c|c|c|c|c|}
\hline & $\begin{array}{l}\text { Intra-assay Precision, } \\
\text { Mean } \pm S D, \mu \mathrm{g} / \mathrm{mL}\end{array}$ & $\mathbf{C V}{ }^{\mathrm{c}}, \%$ & $\begin{array}{l}\text { Inter-assay Precision, } \\
\text { Mean } \pm \mathrm{SD}, \mu \mathrm{g} / \mathrm{mL}\end{array}$ & $\mathrm{CV}, \%$ \\
\hline \multicolumn{5}{|c|}{ High performance liquid chromatography } \\
\hline Level I & $43.29 \pm 1.94$ & 4.48 & $44.29 \pm 2.93$ & 6.61 \\
\hline Level II & $105.50 \pm 5.25$ & 5.18 & $101.88 \pm 6.81$ & 6.69 \\
\hline Level III & $150.35 \pm 6.62$ & 4.40 & $150.70 \pm 10.20$ & 6.77 \\
\hline \multicolumn{5}{|c|}{ Gas chromatography } \\
\hline Level I & $42.99 \pm 1.66$ & 3.86 & $44.09 \pm 2.71$ & 6.14 \\
\hline Level II & $100.70 \pm 3.97$ & 3.95 & $101.48 \pm 6.46$ & 6.36 \\
\hline Level III & $149.65 \pm 5.97$ & 3.99 & $149.61 \pm 9.61$ & 6.42 \\
\hline
\end{tabular}

Table 3. Recovery of Valproic Acid Added to Blank Pool Serum for HPLC ${ }^{a}$ and GC ${ }^{a}$

\begin{tabular}{|c|c|c|c|c|c|}
\hline \multirow{2}{*}{$\begin{array}{l}\text { Blank Pool Serum, } \\
\mu \mathrm{g} / \mathrm{mL}\end{array}$} & \multirow{2}{*}{$\begin{array}{l}\text { Added Valproic Acid, } \\
\mu \mathrm{g} / \mathrm{mL}\end{array}$} & \multicolumn{2}{|c|}{$\begin{array}{l}\text { High Performance Liquid Chromatography, } \\
\text { Mean } \pm \text { SD }\end{array}$} & \multicolumn{2}{|c|}{$\begin{array}{c}\text { Gas Chromatography, } \\
\text { Mean } \pm \text { SD }\end{array}$} \\
\hline & & Measured $^{\mathrm{a}}$ & Recovered & Measured $^{\mathrm{a}}$ & Recovered \\
\hline 0 & 75 & $74.3 \pm 1.53$ & $93.3 \pm 3.1$ & $75.6 \pm 1.80$ & $94.6 \pm 2.5$ \\
\hline
\end{tabular}




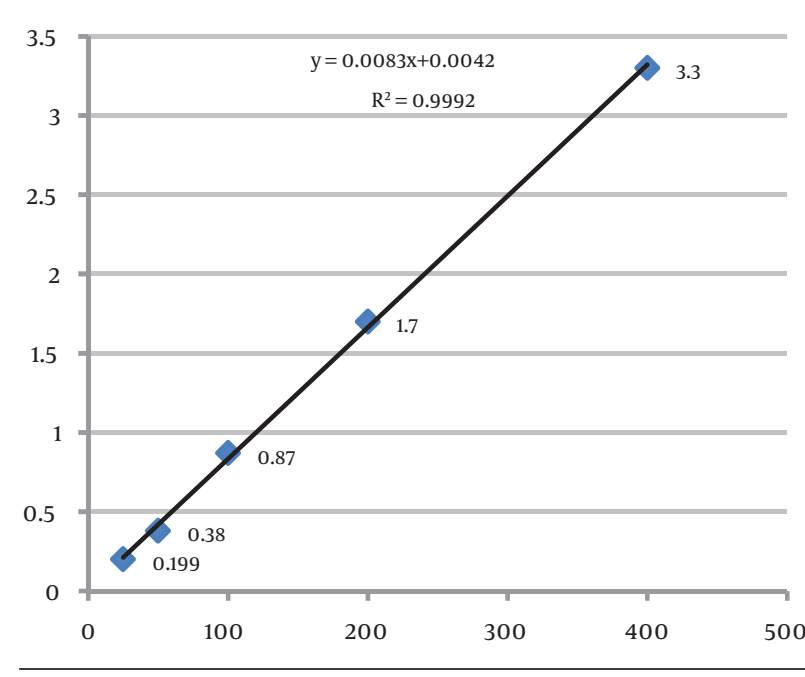

Figure 1. High Performance Liquid Chromatography Linearity

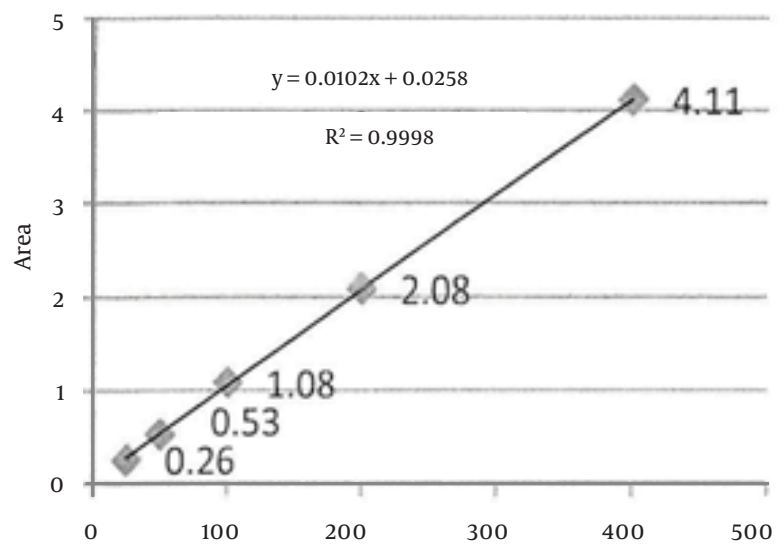

Figure 2. Gas Chromatography Linearity

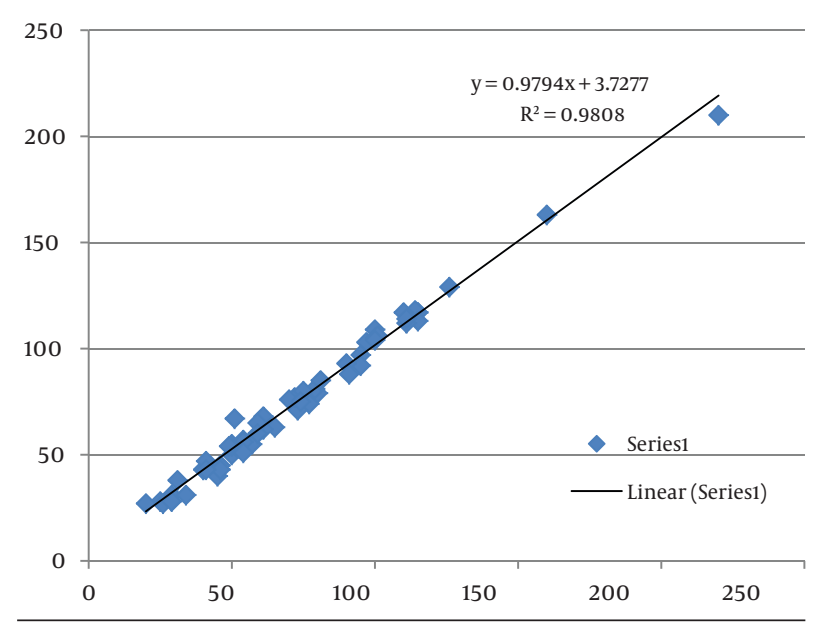

Figure 3. Comparison of Methods

\section{Discussion}

Several different methods have been proposed for the determination of valproic acid in patients' serum samples (6-10). However, studies focusing on direct determination of valproic acid concentration in patients with epilepsy are extremely limited. Direct determination of valproic acid is difficult and, in most of the previously described GC or HPLC methods, a derivatization step after deproteinization with acetonitrile (14-16) prior to chromatographic analysis is required. These procedures are susceptible to associate with poor reproducibility (14). In addition, some of the analytic procedures may require specific detectors (15) that influence the cost of the procedures. Recently, immunological assays have become attractive for routine clinical monitoring during chronic therapy. However, in some cases they are subjected to cross reactive interference problems as well (10, 17-19).

In the present study, we developed an improved method for comparing and evaluating the determination of valproic acid using two systems (HPLC and GC). Our results in both systems agreed satisfactorily regarding linearity, correlation, and recovery studies. The obtained result for the correlation study was in agreement with previous finding (6). In another study, a minimum detectable limit of 0.5 $\mu \mathrm{g} / \mathrm{mL}$ was reported using a derivatizing agent for the GC system (14). Our findings revealed a superior precision for the GC system; however, the limit of quantification of 8.0 $\mu \mathrm{g} / \mathrm{mL}$ without using any derivatizing agent was reached. Furthermore, in our described GC method, the preparation step of the samples was simple and no derivatization and no complex instrument set up were required. Moreover, a higher quality of produced chromatographs and shorter run time of peaks by GC were obtained, which illustrate a good performance of the GC method for valproic acid determination among other proposed methods, especially when comparing with the HPLC system. Thus, in a laboratory analysis when making a choice for valproic acid determination either by GC or by HPLC, the proposed GC method in this study can be successfully applied for the routine quantification of valproic acid levels in patients' serum specimens.

\section{Acknowledgements}

We would like to express our gratitude to the Noor pathobiology laboratory technologists who were involved in the analysis of data.

\section{Authors' Contribution}

Study concept and design: Mehri Aliasgharpour; data analysis and interpretation: Ali Nazeri, Maryam Jalali and Farideh Khosravie; manuscript drafting: Mehri Aliasgharpour; critical revisions of the manuscript for important intellectual contents: Mehri Aliasgharpour. 


\section{Financial Disclosure}

There is no financial disclosure related to the materials in this manuscript.

\section{Funding/Support}

No fund or support was granted to this manuscript.

\section{References}

1. Bowden CL, Singh V. Valproate in bipolar disorder: 2000 onwards. Acta Psychiatr Scand Suppl. 2005;(426):13-20.

2. Perucca E. Pharmacological and therapeutic properties of valproate: a summary after 35 years of clinical experience. CNS Drugs. 2002;16(10):695-714.

3. Haddad PM, Das A,Ashfaq M, Wieck A. A review of valproate in psychiatric practice. Expert Opin Drug Metab Toxicol. 2009;5(5):539-51.

4. DeVane CL. Pharmacokinetics, drug interactions, and tolerability of valproate. Psychopharmacol Bull. 2003;37 Suppl 2:25-42.

5. Bentué-Ferrer D, Tribut O, Verdier MC. [Therapeutic drug monitoring of valproate]. Therapie. 2009;65(3):233-240.

6. Kazuko K, Mikio N, Ryota N, Satoshi K. Direct method for determination of valproic acid in serum by HPLC. Analytical Sci.1985;1:385-7.

7. Wohler AS, Poklis A. A simple, rapid gas-liquid chromatographic procedure for the determination of valproic acid in serum.JAnal Toxicol.1997;21(4):306-9.

8. Berry DJ, Clarke LA. Determination of valproic acid (dipropylacetic acid) in plasma by gas-liquid chromatography. J Chromatogr. 1978;156(2):301-7.

9. Hershey AE, Patton JR, Dudley KH. Gas chromatographic method for the determination of valproic acid in human plasma. Ther Drug Monit. 1979;1(2):217-41.
10. Leroux M, Budnik D, Hall K, Irvine-Meek J, Otten N, Seshia S. Comparison of gas-liquid chromatography and EMIT assay for serum valproic acid. Clin Biochem. 1981;14(2):87-90.

11. Irshaid YM, Hamdi AA, Al Homrany M. Evaluation of therapeutic drug monitoring of antiepileptic drugs. Int J Clin Pharmacol Ther. 2003;41(3):126-31

12. Bowers LD, Armbruster DA, Cairns T, Cody MJT, Fitzgerald R, Goldberger BA, et al. Gas Chromatography/Mass Spectrometry (GC/MS) Confirmation of Drugs; Approved Guideline. NCCLS; 2002. Available from: http://rapidexams.com/v/vspfiles/assets/images/gas\%20 chromatography_mass\%20spectrometry.pdf.

13. Dowling S. Gas chromatography. In: Moffat AC, Osselton D, Widdop B, Galichet LV, Clarke EGC, editors. Clarke's analysis of drugs and poisons: in Pharmaceuticals, body fluids and postmortem material. 3 ed. Pharmaceutical Pres; 2004.

14. Kebriaeizadeh A, Valaie M, Zarghi A. Determination of valproic acid in human plasma by gas chromatography. Pharm Pharmacol Commun. 1998;4(11):525-7.

15. Hara S, Kamura M, Inoue K, Fukuzawa M, Ono N, Kuroda T. Determination of valproic acid in human serum by high-performance liquid chromatography with fluorescence detection. Biol Pharm Bull. 1999;22(9):975-7.

16. Liu H, Forman LJ, Montoya J, Eggers C, Barham C, Delgado M. Determination of valproic acid by high-performance liquid chromatography with photodiode-array and fluorescence detection. JChromatogr B: Biomed Sci Appl. 1992;576(1):163-9.

17. Elyas AA, Goldberg VD, Ratnaraj N, Lascelles PT. Valproic acid estimation by enzyme immunoassay. Ann Clin Biochem. 1980;17(6):307-10.

18. Godolphin W, Trepanier J, Farrell K. Serum and plasma for total and free anticonvulsant drug analyses: effects on EMIT assays and ultrafiltration devices. Ther Drug Monit. 1983;5(3):319-23.

19. Kumps AH. Therapeutic drug monitoring: a comprehensive and critical review of analytical methods for anticonvulsive drugs. $J$ Neurol.1982;228(1):1-16. 